\title{
Impact of varying degrees of renal dysfunction on transcatheter and surgical aortic valve replacement
}

\author{
Tom C. Nguyen, MD, ${ }^{a}$ Vasilis C. Babaliaros, MD, ${ }^{b}$ Seyed Amirhossein Razavi, MD, ${ }^{a}$ Patrick D. Kilgo, MS, \\ Robert A. Guyton, MD, ${ }^{a}$ Chandan M. Devireddy, MD, ${ }^{b}$ Christian C. Shults, MD, ${ }^{a}$ \\ Kreton Mavromatis, MD, ${ }^{\mathrm{b}}$ Mihir Kanitkar, MD, ${ }^{\mathrm{b}}$ Peter Block, MD, ${ }^{\mathrm{b}}$ Stamatois Lerakis, MD, ${ }^{\mathrm{b}}$ and \\ Vinod H. Thourani, MD
}

Background: Renal impairment portends adverse outcomes in patients undergoing valvular heart surgery. The relationship between renal dysfunction in patients undergoing transcatheter aortic valve replacement (TAVR) is incompletely understood.

Methods: A retrospective review of 1336 patients undergoing surgical aortic valve replacement (SAVR; 2002-2012) and 321 patients undergoing TAVR (2007-2012) was performed. Patients were divided into 3 glomerular filtration rate (GFR) groups: GFR greater than $60 \mathrm{~mL} / \mathrm{min}$, GFR 31 to $60 \mathrm{~mL} / \mathrm{min}$, and GFR 30 $\mathrm{mL} / \mathrm{min}$ or less. Logistic and linear regression analysis was performed to estimate the TAVR effect on outcomes. Risk adjustments were made using the Society for Thoracic Surgeons (STS) predicted risk of mortality (PROM).

Results: TAVR patients were older ( 82 vs 65 years; $P<.001)$, had a poorer ejection fraction $(48 \%$ vs $53 \%$; $P<.001)$, were more likely female $(45 \%$ vs $41 \% ; P=.23)$, and had a higher STS PROM $(11.9 \%$ vs $4.6 \%$; $P<.001)$. In-hospital mortality rates for TAVR and SAVR were $3.5 \%$ and $4.1 \%$, respectively $(P=.60)$, a result that marginally favors TAVR after risk adjustment (adjusted odds ratio $=.52, P=.06$ ). In SAVR patients, worsening preoperative renal failure was associated with increased in-hospital mortality $(P=.004)$ and hospital $(P<.001)$ and intensive care unit $(\mathrm{ICU})(P<.001)$ lengths of stay. In contrast, worsening renal function did not influence in-hospital mortality $(P=.78)$ and hospital $(P<.23)$ and ICU $(P=.88)$ lengths of stay in TAVR patients.

Conclusions: Worsening renal function was associated with increased in-hospital mortality, hospital length of stay, and ICU length of stay in SAVR patients, but not in TAVR patients. This unexpected finding may have important clinical implications in patients with aortic stenosis and preoperative renal dysfunction. (J Thorac Cardiovasc Surg 2013;146:1399-407)

\section{Earn CME credits at}

http://cme.ctsnetjournals.org

Preexisting renal dysfunction (RD) is common among patients undergoing surgical aortic valve replacement (SAVR), with up to $75 \%$ of patients having mild $(47.7 \%)$, moderate $(26.7 \%)$, or severe $(2.5 \%)$ renal impairment. ${ }^{1}$ Moreover, we and others have shown that preoperative RD in those undergoing SAVR portends an adverse prognosis,

\footnotetext{
From the Cardiothoracic Surgery Clinical Research Unit, ${ }^{\text {a }}$ Division of Cardiothoracic Surgery, and Division of Cardiology, ${ }^{\mathrm{b}}$ Structural Heart and Valve Center, and Division of Biostatistics, ${ }^{\mathrm{c}}$ Rollins School of Public Health, Emory University School of Medicine, Atlanta, Ga.

This study was supported by internal funds from the Division of Cardiothoracic Surgery Clinical Research Unit.

Disclosures: Authors have nothing to disclose with regard to commercial support.

Read at the 93rd Annual Meeting of The American Association for Thoracic Surgery, Minneapolis, Minnesota, May 4-8, 2013.

Received for publication May 7, 2013; revisions received June 4, 2013; accepted for publication July 26, 2013; available ahead of print Sept 26, 2013.

Address for reprints: Vinod H. Thourani, MD, Division of Cardiothoracic Surgery, Emory University Hospital Midtown, 550 Peachtree St NE, Floor 6 Medical Office Tower, Cardiac Surgery, Atlanta, GA 30308 (E-mail: vthoura@emory.edu). $0022-5223 / \$ 36.00$

Copyright (c) 2013 by The American Association for Thoracic Surgery http://dx.doi.org/10.1016/j.jtcvs.2013.07.065
}

with in-hospital mortality of $2.9 \%$ in patients with no RD, $15 \%$ in patients with severe RD, and $17 \%$ in patients requiring hemodialysis..$^{1-5}$ In this patient demographic in which $\mathrm{RD}$ is prevalent, treatment modalities that minimize the deleterious effect on kidney function are preferred. Recently, transcatheter aortic valve replacement (TAVR) has emerged as a promising therapeutic alternative for high-risk patients with severe aortic stenosis., ${ }^{2,3}$ Despite the allure, impaired renal function at baseline, as measured by estimated glomerular filtration rate (GFR), represents a strong independent predictor of adverse shortand long-term outcome in TAVR patients. ${ }^{4}$ Furthermore, most studies focus on severe RD and end-stage renal disease (ESRD); consequently, the relationship with lesser degrees of RD for TAVR has been incompletely characterized. ${ }^{5,6}$ The objective of this study was to use GFR as an overall measure of kidney function to analyze short-, mid-, and long-term outcomes within SAVR and TAVR patients with varying degrees of preoperative renal impairment.

\section{METHODS}

\section{Subjects and Sample}

Medical records for all consecutive isolated aortic valve replacements between January 1, 2002, and September 12, 2012, at Emory Healthcare 


Abbreviations and Acronyms
$\begin{array}{ll}\text { AKI } & =\text { acute kidney injury } \\ \text { EF } & =\text { ejection fraction } \\ \text { ESRD } & =\text { end-stage renal disease } \\ \text { GFR } & =\text { glomerular filtration rate } \\ \text { ICU } & =\text { intensive care unit } \\ \text { OR } & =\text { odds ratio } \\ \text { PARTNER } & =\text { Placement of Aortic Transcatheter } \\ & \text { Valve } \\ \text { PROM } & =\text { predicted risk of mortality } \\ \text { RD } & =\text { renal dysfunction } \\ \text { SAVR } & =\text { surgical aortic valve replacement } \\ \text { STS } & =\text { Society for Thoracic Surgeons } \\ \text { TAVR } & =\text { transcatheter aortic valve replacement }\end{array}$

Hospitals were gathered for analysis. The time frame includes the entire series of isolated TAVR cases $(2007-2012 ; \mathrm{n}=321)$ and SAVR cases (2002-2012; $\mathrm{n}=1336)$. Three patients were excluded from the analysis because of irretrievable creatinine levels, a component of the primary study variable. This sample of patients was included in the institution's Society for Thoracic Surgeons (STS) Adult Cardiac Database. This study was Health Insurance Portability and Accountability Act compliant, and its approval was subject to Institutional Review Board review.

\section{Measurements}

The primary study variables were surgery type (SAVR or TAVR) and GFR class stratified by classification defined by the National Kidney Foundation: mild or normal (GFR $>60$ ), moderate $(30<\mathrm{GFR} \leq 60)$, or severe or dialysis (GFR $\leq 30$ or preoperative dialysis). ${ }^{7}$ The GFR was estimated according to the Modification of Diet in Renal Disease study equation. Preoperative, operative, and postoperative outcomes were summarized by these 2 variables. Preoperative variables of interest are listed in Table 1, and operative and postoperative variables are shown in Table 2.

Missing data among preoperative predictors were present in small quantities: body mass index $(n=9,0.5 \%)$, hematocrit $(n=78,4.7 \%)$, hemoglobin $(\mathrm{n}=81,4.9 \%)$, hemoglobin $\mathrm{A}_{1 \mathrm{c}}(\mathrm{n}=292,17.6 \%)$, height $(\mathrm{n}=2$, $0.1 \%)$, weight $(n=1,0.1 \%)$, ejection fraction $(n=88,5.3 \%)$, and predicted risk of mortality $(n=9,0.5 \%)$. When adjusting for the covariates with missing data in regression models, a multiple imputation technique was used by which "placeholder" values were imputed by a maximum likelihood algorithm for the missing values. This process was repeated 10 times, and the regression estimates from these imputations were combined and reported. The goal of the imputation is to maximize the use of the existing data, not to recreate the missing data.

\section{Statistical Analysis}

Comparisons of study variables across GFR classes within the strata of TAVR and within the strata of SAVR were made within surgery type using analysis of variance for numerical variables and $\chi^{2}$ tests for categorical variables (Tables 1 and 2). This study was not designed as a superiority study, but rather to examine different patterns within SAVR and within TAVR groups. Changes in GFR from baseline to discharge were evaluated using paired $t$ tests. Also, Kaplan-Meier analysis was used to estimate long-term survival end points at various postoperative points of time. Also, to control for selection bias, multivariable logistic (for clinical end points) and linear (for numerical outcomes) models were constructed to test for the independent effects of surgery and GFR burden. Adjustments were end point specific, pre-hoc, and included patient age, white race, chronic lung disease, redo status, ejection fraction (EF), insulin dependence, sex, immunocompromised, emergent status, stroke, and peripheral vascular disease. Logistic models were fit for death, stroke, dialysis, and worsening renal failure. Linear regression models were used for length of stay and intensive care unit (ICU) hours. Adjusted odds ratios and $95 \%$ confidence intervals were calculated for each comparison. SAVR was the reference group for surgery comparisons, and "normal" or "mild" was the reference for GFR burden. Three separate models were constructed for each outcome: (1) a model comparing the effect of SAVR with TAVR on all patients, (2) a comparison of GFR burden within SAVR, and (3) a comparison of GFR burden within TAVR.

Cox proportional hazards regression was used for the following: (1) to test the effects of surgery type and GFR burden on long-term survival and (2) to test for interaction between surgery and GFR group. A significant interaction was detected $(P<.001)$, meaning that the effect of GFR burden on survival was different in TAVR patients than in SAVR patients. Thus, a stratified regression approach was used to characterize the interaction. Separate Cox models were fit within SAVR and TAVR patients separately. Adjusted hazard ratios and $95 \%$ confidence intervals were reported after adjustment with the STS predicted risk of mortality score (PROM), a known covariate of survival.

The Social Security Death Index, in conjunction with hospital records, was queried for death dates of each study patient. The death dates were collected on February 29, 2012; patients alive on that date were considered censored for survival analyses. Patients operated on after this date had no long-term survival follow-up and, thus, were excluded from all survival analyses.

\section{RESULTS \\ Baseline Characteristics}

Table 1 describes baseline demographic and clinical characteristics of preoperative variables for SAVR and TAVR, stratified by GFR burden. The average ages for TAVR and SAVR patients were $82.2 \pm 8.2$ and $65.2 \pm 14.6$ years, respectively. TAVR patients were older than SAVR patients, but also had a lower EF across varying degrees of GFR burden and higher STS PROM. The PROM increased for both SAVR and TAVR with increased GFR burden: TAVR (mild, $0.10 \pm 0.05$; moderate, $0.13 \pm 0.07$; and severe/dialysis, $0.21 \pm 0.13$ ) and SAVR (mild, $0.03 \pm 0.02$; moderate, $0.06 \pm 0.05$; and severe/dialysis, $0.14 \pm 0.12$ ).

\section{Preoperative and Postoperative Clinical End Points}

Operative and postoperative clinical end points for SAVR and TAVR, stratified by GFR burden, are described in Table 2. For SAVR, the incidence of new dialysis and worsening renal failure increased with worsening renal function $(P<.001$ for both). However, for TAVR, there was no statistical significance with worsening preoperative renal function and need for new postoperative dialysis and RD $(P=.78)$. Similarly, for SAVR, ventilation and ICU hours increased with worsening renal function $(P<.001$ for both), whereas for TAVR, there was no association between ventilation hours $(P=.87)$ or ICU hours $(P=.89)$ and GFR burden. The average hospital length of stay for the SAVR patients increased with the worsening of the GFR class (mild, $7.6 \pm 5.8$ days; moderate, $9.7 \pm 7.7$ days; severe/dialysis, $13.0 \pm 9.8$ days; $P<.001)$, but this was not the case for TAVR patients $(P=.15)$. 
TABLE 1. Demographic and clinical characteristics by surgery type and GFR burden

\begin{tabular}{|c|c|c|c|c|c|c|c|c|}
\hline & \multicolumn{4}{|c|}{ SAVR $(N=1336)$} & \multicolumn{4}{|c|}{$\operatorname{TAVR}(\mathbf{N}=\mathbf{3 2 1})$} \\
\hline & $\begin{array}{c}\text { None/mild } \\
(n=915)\end{array}$ & $\begin{array}{l}\text { Moderate } \\
(\mathbf{n}=\mathbf{3 2 0})\end{array}$ & $\begin{array}{c}\text { Severe/dialysis } \\
(\mathbf{n}=101)\end{array}$ & $P$ value & $\begin{array}{c}\text { None/mild } \\
(\mathbf{n}=159)\end{array}$ & $\begin{array}{l}\text { Moderate } \\
(\mathbf{n}=139)\end{array}$ & $\begin{array}{c}\text { Severe/Dialysis } \\
\quad(n=23\end{array}$ & $P$ value \\
\hline Age, y & $63.1 \pm 15.1$ & $72.7 \pm 10.0$ & $60.7 \pm 15.1$ & $<.001$ & $81.7 \pm 9.1$ & $83.4 \pm 6.9$ & $79.6 \pm 8.4$ & .047 \\
\hline BMI, $\mathrm{kg} / \mathrm{m}^{2}$ & $28.4 \pm 6.2$ & $28.7 \pm 6.5$ & $28.7 \pm 7.3$ & .71 & $25.9 \pm 4.8$ & $27.3 \pm 6.1$ & $28.0 \pm 6.3$ & .037 \\
\hline $\mathrm{EF}$ & $54.2 \pm 12.8$ & $51.5 \pm 14.2$ & $51.7 \pm 12.0$ & .004 & $49.0 \pm 12.8$ & $48.8 \pm 14.8$ & $39 \pm 16.4$ & .005 \\
\hline PROM & $0.03 \pm 0.02$ & $0.06 \pm 0.05$ & $0.14 \pm 0.12$ & $<.001$ & $0.10 \pm 0.05$ & $0.13 \pm 0.07$ & $0.21 \pm 0.13$ & $<.001$ \\
\hline White & $744(81.3)$ & $283(88.4)$ & $46(45.5)$ & $<.001$ & $147(92.5)$ & $130(93.5)$ & $19(82.6)$ & .19 \\
\hline Female sex & $333(36.4)$ & $167(52.2)$ & $48(47.5)$ & $<.001$ & $61(38.4)$ & $72(51.8)$ & $9(39.1)$ & .06 \\
\hline Cerebrovascular disease & $140(15.3)$ & $75(23.4)$ & $13(12.9)$ & .002 & $48(30.2)$ & $43(30.9)$ & $12(52.2)$ & .10 \\
\hline COPD & $172(18.8)$ & $89(27.8)$ & $25(24.7)$ & .035 & $77(48.4)$ & 69 (49.6) & $11(47.8$ & .90 \\
\hline Diabetes & $212(23.2)$ & $115(35.9)$ & $47(46.5)$ & $<.001$ & $69(43.3)$ & $59(42.5)$ & $12(52.2)$ & .68 \\
\hline Preoperative creatinine & $0.93 \pm 19$ & $1.37 \pm 0.28$ & $5.4 \pm 2.9$ & $<.001$ & $0.92 \pm 0.20$ & $1.40 \pm 0.29$ & $3.4 \pm 2.0$ & $<.001$ \\
\hline Dyslipidemia & $552(60.3)$ & $206(64.4)$ & $50(49.5)$ & .028 & 144 (90.6) & $123(88.5)$ & $23(100.0)$ & .22 \\
\hline Hypertension & $692(75.6)$ & 278 (86.9) & $96(95.1)$ & $<.001$ & $148(93.1)$ & $135(97.1)$ & $22(95.7)$ & .28 \\
\hline PVD & $78(8.5)$ & $39(12.2)$ & $21(20.8)$ & $<.001$ & $53(33.3)$ & $44(31.7)$ & $14(60.9)$ & .022 \\
\hline CVA & $77(8.4)$ & $36(11.3)$ & $7(6.9)$ & .24 & $25(15.7)$ & $19(13.7)$ & $8(34.8)$ & .038 \\
\hline Previous CABG & $98(10.7)$ & $52(16.3)$ & $17(16.8)$ & .014 & $65(40.9)$ & $46(33.1)$ & $9(39.1)$ & .38 \\
\hline Previous valve & $84(9.2)$ & $33(10.3)$ & $10(9.9)$ & .83 & $31(19.5)$ & $26(18.7)$ & $10(43.5)$ & .021 \\
\hline Redo & 179 (19.6) & $79(24.7)$ & $26(25.7)$ & .08 & $80(50.3)$ & $61(43.9)$ & $11(47.8)$ & .54 \\
\hline Preoperative IABP & $2(0.2)$ & $1(0.3)$ & $2(2.0)$ & .022 & $0(0.0)$ & $2(1.4)$ & $1(4.4)$ & .09 \\
\hline
\end{tabular}

Data are given as mean \pm SD or number (percentage). GFR, Glomerular filtration rate; $S A V R$, surgical aortic valve replacement; TAVR, transcatheter aortic valve replacement; $B M I$, body mass index; $E F$, ejection fraction; $P R O M$, predicted risk of mortality; $C O P D$, chronic obstructive pulmonary disease; $P V D$, peripheral vascular disease; $C V A$, cerebrovascular disease; $C A B G$, coronary artery bypass grafting; IABP, intra-aortic balloon pump.

The percentages of patients undergoing hemodialysis in the severe RD for SAVR $(n=61)$ and TAVR $(n=8)$ groups were $60 \%$ and $34 \%$, respectively. The corresponding death rates for SAVR and TAVR were $14.8 \%(\mathrm{n}=9)$ and $0 \%$ $(\mathrm{n}=0)$, respectively.

Figure 1 depicts in-hospital mortality for SAVR and TAVR patients grouped by varying degrees of RD. For SAVR patients, worsening GFR was associated with increased in-hospital mortality (mild, 2.6\%; moderate, $4.1 \%$; severe, $8.9 \% ; P=.004)$. Worsening GFR, however, was not associated with increased in-hospital mortality for TAVR patients (mild, 3.8\%; moderate, $2.9 \%$; severe, $4.4 \% ; P=.89)$. The solid line and dot in the figure represent the STS PROM stratified by varying degrees of RD. For both SAVR and TAVR, a stepwise increase in the STS PROM was appreciated with worsening renal function.

TABLE 2. Operative and postoperative clinical end points by surgery type and GFR burden

\begin{tabular}{|c|c|c|c|c|c|c|c|c|}
\hline & \multicolumn{4}{|c|}{ SAVR $(N=1336)$} & \multicolumn{4}{|c|}{$\operatorname{TAVR}(\mathbf{N}=\mathbf{3 2 1})$} \\
\hline & $\begin{array}{c}\text { None/mild } \\
(\mathrm{n}=915)\end{array}$ & $\begin{array}{l}\text { Moderate } \\
(\mathbf{n}=\mathbf{3 2 0})\end{array}$ & $\begin{array}{l}\text { Severe/dialysis } \\
\quad(\mathbf{n}=101)\end{array}$ & $P$ value & $\begin{array}{c}\text { None/mild } \\
(\mathbf{n}=159)\end{array}$ & $\begin{array}{l}\text { Moderate } \\
(\mathbf{n}=139)\end{array}$ & $\begin{array}{c}\text { Severe/dialysis } \\
\quad(n=23)\end{array}$ & $P$ value \\
\hline Intraoperative IABP & $37(4.0)$ & $25(7.8)$ & $9(8.9)$ & .009 & $8(5.0)$ & $5(3.6)$ & $0(0.0)$ & .49 \\
\hline Postoperative IABP & $8(0.9)$ & $2(0.6)$ & $0(0.0)$ & .60 & $1(0.6)$ & $0(0.0)$ & $0(0.0)$ & .60 \\
\hline Postoperative transfusion & $573(62.6)$ & $250(78.1)$ & $86(85.2)$ & $<.001$ & $66(41.5)$ & $68(48.9)$ & $9(39.1)$ & .38 \\
\hline Stroke & $24(2.6)$ & $7(2.2)$ & $6(5.9)$ & .12 & $2(1.3)$ & $2(1.4)$ & $1(4.4)$ & .53 \\
\hline Atrial fibrillation & $220(24.0)$ & $110(34.4)$ & $31(30.7)$ & .001 & $13(8.2)$ & $9(6.5)$ & $2(8.7)$ & .83 \\
\hline Pneumonia & $31(3.4)$ & $19(5.9)$ & $9(8.9)$ & .012 & $9(5.7)$ & $3(2.2)$ & $0(0.0)$ & .17 \\
\hline New dialysis & $10(1.1)$ & $9(2.8)$ & $10(9.9)$ & $<.001$ & $3(1.9)$ & $3(2.2)$ & $0(0.0)$ & .78 \\
\hline Worsening RF & $29(3.2)$ & $14(4.4)$ & $12(11.9)$ & $<.001$ & $5(3.1)$ & $3(2.2)$ & $0(0.0)$ & .63 \\
\hline Bleeding & $31(3.4)$ & $12(3.8)$ & $7(6.9)$ & .21 & $1(0.6)$ & $2(1.4)$ & $0(0.0)$ & .68 \\
\hline Crossclamp Time, min & $81.2 \pm 24.4$ & $78.5 \pm 23.9$ & $87.0 \pm 23.9$ & .009 & - & - & - & - \\
\hline Ventilation, h & $34.1 \pm 109.3$ & $49.7 \pm 129.2$ & $95.6 \pm 169.4$ & $<.001$ & $30.6 \pm 85.3$ & $35.0 \pm 145.6$ & $20.4 \pm 17.2$ & .87 \\
\hline ICU, h & $73.1 \pm 121.6$ & $102.4 \pm 147.2$ & $167.4 \pm 207.5$ & $<.001$ & $69.9 \pm 100.6$ & $76.7 \pm 153.5$ & $76.0 \pm 58.1$ & .89 \\
\hline Discharge creatinine & $0.95 \pm 0.29$ & $1.27 \pm 0.48$ & $4.44 \pm 2.57$ & $<.001$ & $0.90 \pm 0.23$ & $1.31 \pm 0.48$ & $3.06 \pm 1.53$ & $<.001$ \\
\hline LOS & $7.6 \pm 5.8$ & $9.7 \pm 7.7$ & $13.0 \pm 9.8$ & $<.001$ & $6.6 \pm 5.2$ & $6.9 \pm 6.6$ & $9.2 \pm 7.3$ & .15 \\
\hline Contrast load & - & - & - & - & $118 \pm 64$ & $111 \pm 80$ & $70 \pm 34$ & .01 \\
\hline
\end{tabular}

$G F R$, Glomerular filtration rate; $S A V R$, surgical aortic valve replacement; $T A V R$, transcatheter aortic valve replacement; $I A B P$, intra-aortic balloon pump; $R F$, renal failure; $I C U$, intensive care unit; $L O S$, length of stay. 


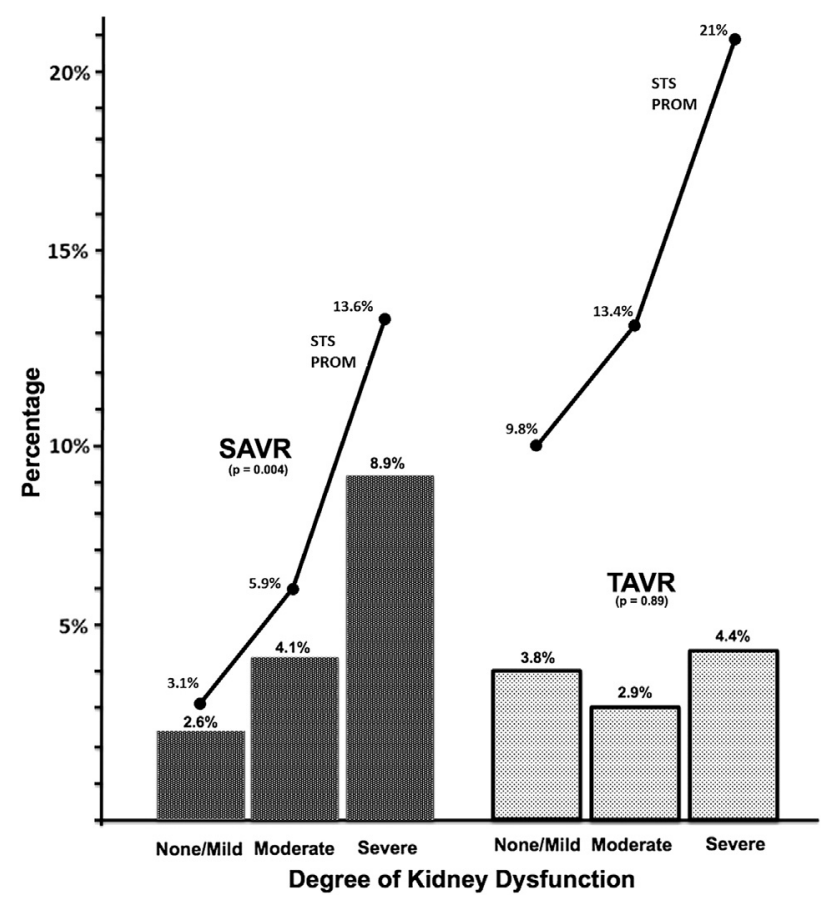

FIGURE 1. In-hospital mortality and Society for Thoracic Surgeons (STS) predicted risk of mortality (PROM), based on the degree of kidney dysfunction in patients undergoing surgical aortic valve replacement $(S A V R)$ and transcatheter aortic valve replacement (TAVR).

Figure 2 represents Kaplan-Meier survival estimates for SAVR and TAVR stratified by varying degrees of RD. For SAVR, there was a stepwise decrease in long-term survival with worsening renal function $(P=.001)$. Decreased renal function, however, was not associated with increased longterm mortality in TAVR $(P=.94)$. The 6-month, 1-year, and 4-year survival rates for all SAVR patients were $91.6 \%$, $89.2 \%$, and $82.4 \%$, respectively. For all TAVR patients, 6-month, 1-year, and 4-year survival rates were $87.2 \%$, $79.3 \%$, and $26.8 \%$, respectively.

Table 3 depicts GFR burden by contrast load, procedure, and TAVR access. The range of contrast used in our study was 1 to $150 \mathrm{~mL}$ (mean, $109 \pm 61 \mathrm{~mL}$ ). Irrespective of the amount of contrast used, postoperative GFR increased relative to preoperative GFR. Furthermore, when adjusting for covariates and STS predicted risk of renal failure, contrast load was not associated with increased incidence of renal failure (odds ratio [OR], 0.998; $P=.80$ ) or dialysis (OR, 0.998; $P=.72$ ). Both SAVR and TAVR resulted in increased GFR, with a change of 2.6 and 5.3, respectively. The change in GFR was greater in TAVR than in SAVR $(P=.02)$.

In all patients, the adjusted odds ratio for death was 0.47 when comparing TAVR with SAVR (Table 4). In SAVR patients, the adjusted odds ratio for death was 2.6 when comparing severe/dialysis with normal patients. In TAVR patients, the odds ratio was 1.01 when comparing severe/ dialysis with normal patients. Worsening GFR increased the hazard for death for SAVR but not for TAVR. In SAVR patients with moderate and severe RD, the hazards for death were $77 \%$ and $180 \%$ higher than the hazards for patients with normal renal function, respectively.

\section{DISCUSSION}

A strong association exists between valvular heart disease, particularly aortic stenosis, and renal dysfunction, with up to $75 \%$ of patients having mild, moderate, or severe RD. ${ }^{1}$ In patients with ESRD, dystrophic calcification of the aortic annulus and leaflets occurred rapidly and frequently, with onset 10 to 20 years earlier than in the general population. ${ }^{8}$ In patients with RD undergoing SAVR, we have previously shown that impaired GFR is associated with a predictable stepwise increase in adverse short-, mid-, and long-term outcomes. ${ }^{1}$ Because TAVR emerges as an alternative treatment modality for inoperative or high-risk patients with severe aortic stenosis, the relationship between varying degrees of $\mathrm{RD}$ and postoperative outcome is incompletely understood. In this study, we investigated the relationship between varying degrees of RD on short-, mid-, and long-term outcomes in both TAVR and SAVR patients. The following points highlight our results: (1) TAVR mitigates the effect of moderate and severe RD on shortand long-term survival; (2) SAVR and TAVR increased postoperative GFR, but a greater improvement was appreciated after TAVR; and (3) contrast load for TAVR was not associated with increased renal failure or dialysis.

\section{Survival}

Although previous studies have detailed short- and mid-term survival in both SAVR and TAVR, data regarding mortality stratified by GFR are sparse. A meta-analysis conducted by Khatri and colleagues, ${ }^{9}$ including 49 TAVR studies (16,063 patients), revealed 30-day and 1-year survival rates of $91.9 \%$ and $79.2 \%$, respectively. TAVR patients in our study had slightly better 30-day survival (at $96.5 \%$ ) and similar 1-year survival (at 79.3\%). Our survival results were more in congruence with the landmark Placement of Aortic Transcatheter Valve (PARTNER) trial for high-risk patients demonstrating 30-day and 1-year all cause mortality from TAVR of $3.4 \%$ and $24.2 \%$, respectively. ${ }^{3}$ Survival in TAVR patients with renal dysfunction, however, is less understood. It is increasingly recognized that impaired baseline renal function and periprocedural acute kidney injury (AKI) portend adverse short- and long-term outcomes in TAVR patients. In 213 TAVR patients with baseline RD, Bagur and colleagues ${ }^{5}$ report an AKI incidence of $11.7 \%$ and a 4-fold increased risk of postoperative mortality. ${ }^{5}$ The incidence of new or worsening renal failure in our TAVR group was $2.5 \%$ (Table 2). Furthermore, Webb and colleagues ${ }^{10}$ reveal chronic renal failure as an independent predictor for cumulative late 

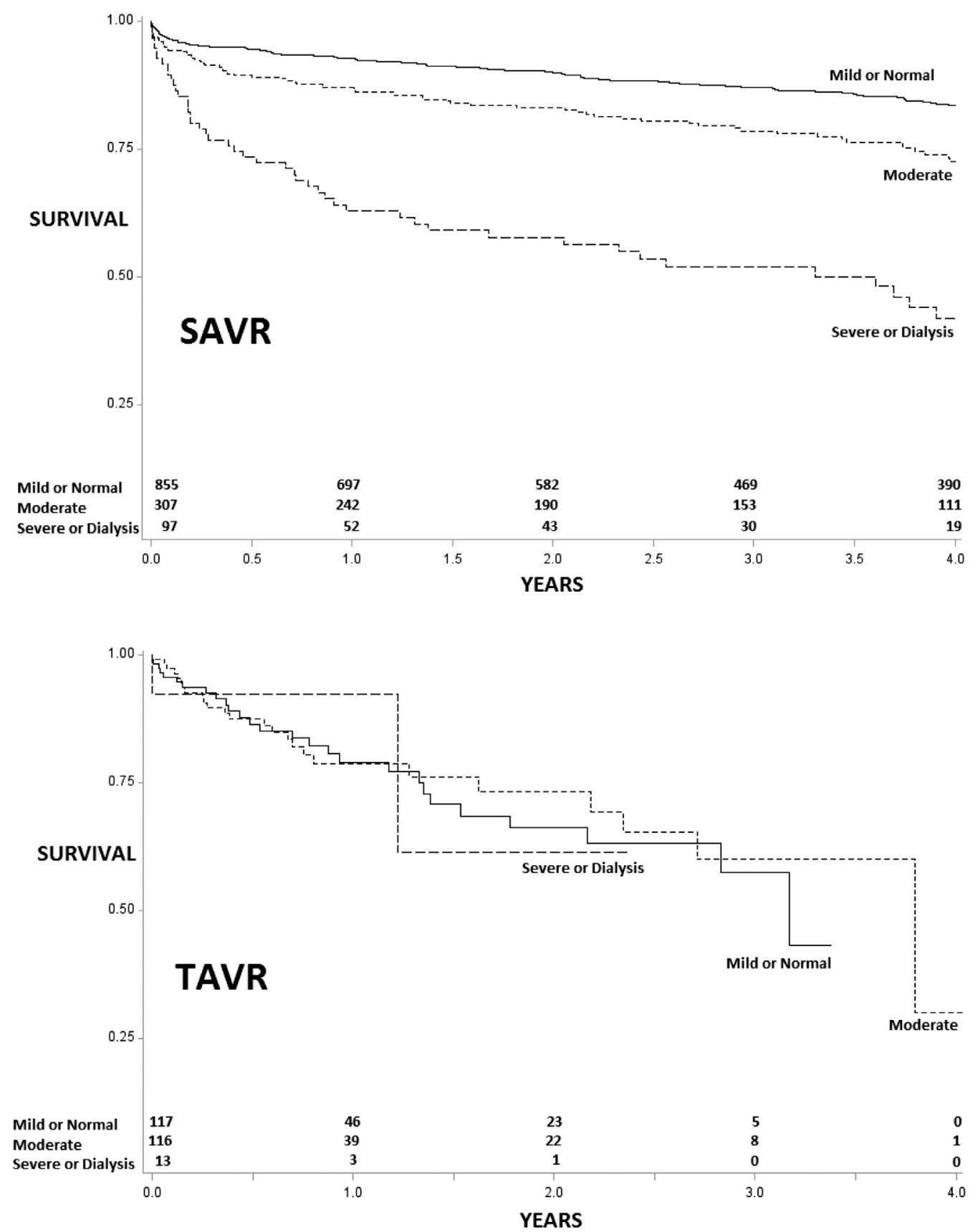

FIGURE 2. Kaplan-Meier survival estimates stratified by renal dysfunction for surgical aortic valve replacement (SAVR) and transcatheter aortic valve replacement $(T A V R)$.

mortality. Although these studies underscore the impact of preoperative and postoperative RD after TAVR, short- and mid-term outcome with varying degrees of GFR has not been described. Our results extend on previous findings by stratifying outcome after TAVR by varying degrees of renal function.

The most provocative results from our study relate to mortality in the TAVR group. In-hospital mortality for mild, moderate, and severe renal dysfunction in our study was $3.8 \%, 2.9 \%$, and $4.4 \%$ (Figure $1, P=.89$ ), respectively. There was no association with in-hospital mortality and worsening renal function. On the contrary, in our SAVR group, worsening renal function was associated with a stepwise increase in short-term mortality, at $2.6 \%$, $4.1 \%$, and $8.9 \%$ for mild, moderate, and severe RD, respectively. Although worsening renal function is strongly associated with increased mid- and long-term mortality in our SAVR group, Kaplan-Meier survival estimates for TAVR 
TABLE 3. Preoperative and postoperative GFR burden by contrast load, procedure, and TAVR access

\begin{tabular}{lrccrc}
\hline \multicolumn{1}{c}{ Variable } & $\begin{array}{c}\text { Sample } \\
\text { size }\end{array}$ & $\begin{array}{c}\text { Preoperative } \\
\text { GFR }\end{array}$ & $\begin{array}{c}\text { Discharge } \\
\text { GFR }\end{array}$ & $\begin{array}{c}\boldsymbol{P} \\
\text { Change }\end{array}$ & value \\
\hline Contrast load, $\mathrm{mL}$ & & & & & \\
$\quad 1-74$ & 86 & 57.4 & 63.1 & 5.7 & $<.001$ \\
$75-149$ & 141 & 60.7 & 65.4 & 4.7 & .003 \\
$\quad 150+$ & 73 & 70.7 & 76.9 & 6.2 & .037 \\
SAVR & 1333 & 71.7 & 74.3 & 2.6 & $<.001$ \\
TAVR & 321 & 61.6 & 67.0 & 5.3 & $<.001$ \\
Transfemoral TAVR & 198 & 61.7 & 67.3 & 5.5 & $<.001$ \\
Transapical TAVR & 99 & 60.3 & 66.4 & 6.1 & $<.001$ \\
Transaortic & 20 & 61.9 & 59.2 & -2.6 & .60 \\
\hline$G F R$,
\end{tabular}

GFR, Glomerular filtration rate; TAVR, transcatheter aortic valve replacement; $S A V R$, surgical aortic valve replacement.

stratified by renal function do not demonstrate this relationship (Figure 2). It appears that TAVR mitigates the effect of moderate and severe RD on short- and mid-term survival. After risk adjustment, the odds ratio estimate for death in severe/dialysis SAVR patients versus patients with no RD was 2.64 (Table $4, P<.05$ ), whereas the observed outcome/expected outcome ratio for similar TAVR patients was 1.0. Our SAVR results corroborate prior findings by our group examining short- and long-term outcome with varying degrees of renal function.

Similar observations were noted with other important outcome variables, specifically, new renal failure, ventilator and ICU hours, and hospital length of stay (Table 2). For these variables, patients in the SAVR group experienced a stepwise increase in adverse outcome as renal function declined. On the contrary, worsening renal function was not associated with worsening outcomes in the TAVR group.

\section{Improved GFR}

Acute renal failure is a common complication after cardiac surgery, occurs in up to $30 \%$ of patients, and is a powerful predictor of adverse outcome independent of all other factors. ${ }^{11}$ In TAVR patients, the incidence of AKI ranges from $11.7 \%$ to $28 \%$, depending on baseline patient characteristics., ${ }^{5,12}$ Proper identification of renal dysfunction is critical in predicting postoperative outcomes, and GFR appears to be the optimal measure for overall kidney function. ${ }^{13}$ Although onset of AKI is an important prognostic variable after cardiac surgery, the effect of SAVR and TAVR on postoperative GFR is incompletely understood.

In our study, we used a nonionic low osmolar contrast agent (Isovue; Bracco Diagnostics Inc, Princeton, NJ) to examine preoperative and postoperative GFR after SAVR and TAVR. Both SAVR and TAVR increased postoperative GFR at discharge, and it appears that TAVR resulted in a greater increase in GFR (change in GFR: SAVR, $2.6 \mathrm{~mL} /$ min per $1.73 \mathrm{~m}^{2}$; TAVR, $5.3 \mathrm{~mL} / \mathrm{min}$ per $1.73 \mathrm{~m}^{2}$ ). Our analysis combined all access approaches for TAVR, including transfemoral $(\mathrm{n}=198,62 \%)$, transapical $(\mathrm{n}=99,31 \%)$, and transaortic $(\mathrm{n}=20,6 \%)$. Both transfemoral and transapical approaches increased postoperative GFR of near-equal magnitude, whereas transaortic approaches did not increase GFR (Table 3). Other investigators have seen similar trends in improvement of GFR after SAVR and TAVR. Aregger and colleagues ${ }^{12}$ evaluated 54 patients after TAVR and reported GFR improvements in $56 \%$ of patients. In a larger study by Van Linden and colleagues, ${ }^{14}$ including 270 patients after transapical TAVR, improved GFR was also noted in more than $50 \%$ of patients. In our study, GFR was improved in $51 \%$ of SAVR and $59.5 \%$ of TAVR patients, respectively $(P=.007)$.

There is a tight association between aortic stenosis and renal dysfunction, presumably from pathomechanisms that promote calcium deposition on aortic leaflets after cyclical mechanical stress. ${ }^{8}$ In patients with ESRD, dystrophic calcification of the aortic annulus and leaflets occurs rapidly and frequently, thereby worsening aortic stenosis. On the other hand, severe aortic stenosis with decreased flow to the kidneys has been suggested as a contributing mechanism for impaired glomerular filtration rate. ${ }^{12}$ As a result, it is conceivable renal dysfunction begets aortic stenosis and aortic stenosis subsequently begets renal dysfunction. The results from our study are insightful in that correction of aortic stenosis by either SAVR or TAVR improves overall kidney function in most patients, and may stop the cycle of aortic stenosis begetting renal dysfunction and vice versa. This underlies the importance and urgency of addressing aortic stenosis in patients with renal dysfunction to improve renal flow.

TABLE 4. Adjusted odds ratio estimates using direct adjustments

\begin{tabular}{|c|c|c|c|c|c|}
\hline & \multirow{2}{*}{$\frac{\text { All patients }(\mathrm{n}=1657)}{\text { TAVR vs SAVR }}$} & \multicolumn{2}{|c|}{ SAVR patients $(n=1336)$} & \multicolumn{2}{|c|}{ TAVR patients $(\mathbf{n}=321)$} \\
\hline & & Moderate vs normal & Severe/dialysis vs normal & Moderate vs normal & Severe/dialysis vs normal \\
\hline Death & $0.47(0.23-0.95)^{*}$ & $1.12(0.58-2.18)$ & $2.64(1.15-6.04)^{*}$ & $0.72(0.21-2.41)$ & $1.01(0.11-9.52)$ \\
\hline Stroke & $0.33(0.12-0.92)^{*}$ & $0.61(0.25-1.48)$ & $1.61(0.57-4.56)$ & $1.12(0.15-8.27)$ & $3.69(0.24-57.62)$ \\
\hline New dialysis & $0.57(0.21-1.56)$ & $2.25(0.83-6.08)$ & $11.94(4.19-34.02)^{*}$ & $1.00(0.18-5.52)$ & - \\
\hline New renal failure & $0.47(0.20-1.08)$ & $1.19(0.59-2.41)$ & $3.76(1.65-8.56)^{*}$ & $0.61(0.13-2.83)$ & - \\
\hline ICU, h & $-49.9 \mathrm{~h}^{*}$ & 7.7 & $77.6^{*}$ & 2.9 & 10.8 \\
\hline LOS, d & $-3.2 *$ & $1.3^{*}$ & $4.4^{*}$ & 0.1 & 2.5 \\
\hline
\end{tabular}

$S A V R$, Surgical aortic valve replacement; TAVR, transcatheter aortic valve replacement; $I C U$, intensive care unit; $L O S$, length of stay. ${ }^{*} P<.05$. 


\section{Contrast Load}

In patients with aortic stenosis in whom preexisting renal dysfunction is prevalent, treatment modalities that minimize the deleterious effect on kidney function are preferred. SAVR requires cardiopulmonary bypass, a recognized risk factor for AKI after cardiac surgery. ${ }^{15}$ On the other hand, TAVR avoids cardiopulmonary bypass, but subjugates the kidneys to a potentially nephrotoxic contrast agent during the procedure. ${ }^{16}$ The mean amount of contrast used in TAVR patients for our study was $109 \pm 61 \mathrm{~mL}$. Patients with none to mild $\mathrm{RD}$ received the most amount of contrast $(118 \pm 64 \mathrm{~mL})$, whereas patients with severe RD received the least amount of contrast $(70 \pm 34 \mathrm{~mL})$ (Table 2). Regardless of the amount of contrast used in our study, GFR improved for most patients. Moreover, contrast load was not associated with increased incidence of renal failure (OR, 0.998; $P=.80$ ) or new-onset dialysis (OR, 0.998; $P=.72$ ) in our multivariable analysis with renal function as an outcome variable. This result also holds when adjusting for the STS predicted risk of renal failure.

Our results are corroborated by several smaller TAVR studies. Podolecka and colleagues ${ }^{17}$ examined preoperative and postoperative creatinine and GFR in 39 TAVR patients with a mean contrast volume of $187 \pm 91 \mathrm{~mL}$. The contrast amount did not correlate with decreased renal function. Additional studies by Strauch and colleagues ${ }^{18}$ in 30 transapical TAVR patients also did not demonstrate a relationship between contrast amount (median, $115 \mathrm{~mL}$ ) and kidney injury.

Our study involving 343 TAVR patients extends on previous studies and further suggests that reasonable amounts of contrast in the range of 1 to $150 \mathrm{~mL}$ is not associated with increased renal failure or dialysis. The authors recognize, however, the potential dose-related nephrotoxic potential of using contrast agents and recommend judicious use in patients with severe renal dysfunction.

\section{Limitations}

Several important limitations are noteworthy when extrapolating results from this study. This represents an observational retrospective database study with inherent limitations. The study was designed as an intragroup comparison to determine trends in outcome with varying degrees of renal dysfunction. Future propensity-matched studies comparing TAVR with SAVR are warranted. This study, however, does provide valuable insight into trends within TAVR and trends within SAVR. We used a single measurement for preoperative and postoperative GFR. Although there is probably little variation in preoperative renal function, we recognize that postoperative GFR is a dynamic variable and cannot exclude that further measurements during the hospitalization may reveal either improved or worse renal function. For our analysis, we elected to use GFR at discharge, with the assumption that renal function had adequately stabilized to reveal a higher or lower incidence of AKI. Last, the authors appreciate the potential for a type II error. Our sample sizes are moderately large, and power calculations are not advisable in retrospective, uncontrolled studies. Our analysis did achieve statistical significance in several predefined end points, suggesting adequate power in the comparisons. This study was not designed as a superiority study, but rather it was designed to look for different patterns of effects on outcomes within TAVR and SAVR subgroups.

\section{CONCLUSIONS}

This represents a large series of SAVR $(n=1336)$ and largest series of TAVR $(\mathrm{n}=343)$ patients examining short-, mid-, and long-term outcomes in patients with varying degrees of preoperative RD and postoperative renal function. Worsening renal function was associated with increased in-hospital and long-term mortality, hospital length of stay, and ICU length of stay in SAVR patients, but not in TAVR patients. TAVR mitigates the effect of renal dysfunction on short- and long-term survival, SAVR and TAVR increased postoperative GFR, and contrast load was not associated with renal failure of dialysis. These findings may have important clinical implications when deliberating between SAVR and TAVR in aortic stenosis patients with preoperative renal dysfunction.

We thank staff members Kim Baio for project oversight and Iman Aziz for data extraction.

\section{References}

1. Thourani VH, Keeling WB, Sarin EL, Guyton RA, Kilgo PD, Dara AB, et al. Impact of preoperative renal dysfunction on long-term survival for patients undergoing aortic valve replacement. Ann Thorac Surg. 2011;91:1798-806; discussion 806-7.

2. Leon MB, Smith CR, Mack M, Miller DC, Moses JW, Svensson LG, et al. Transcatheter aortic-valve implantation for aortic stenosis in patients who cannot undergo surgery. N Engl J Med. 2010;363:1597-607.

3. Smith CR, Leon MB, Mack MJ, Miller DC, Moses JW, Svensson LG, et al. Transcatheter versus surgical aortic-valve replacement in high-risk patients. $N$ Engl J Med. 2011;364:2187-98.

4. Sinning JM, Ghanem A, Steinhäuser H, Adenauer V, Hammerstingl C, Nickenig G, et al. Renal function as predictor of mortality in patients after percutaneous transcatheter aortic valve implantation. JACC Cardiovasc Interv. 2010;3:1141-9.

5. Bagur R, Webb JG, Nietlispach F, Dumont E, De Larochellière R, Doyle D, et al. Acute kidney injury following transcatheter aortic valve implantation: predictive factors, prognostic value, and comparison with surgical aortic valve replacement. Eur Heart J. 2010;31:865-74.

6. Cooper WA, O'Brien SM, Thourani VH, Guyton RA, Bridges CR, Szczech LA, et al. Impact of renal dysfunction on outcomes of coronary artery bypass surgery: results from the Society of Thoracic Surgeons National Adult Cardiac Database. Circulation. 2006;113:1063-70.

7. National Kidney Foundation. K/DOQI clinical practice guidelines for chronic kidney disease: evaluation, classification, and stratification. Am J Kidney Dis 2002;39:S1-266

8. London GM, Pannier B, Marchais SJ, Guerin AP. Calcification of the aortic valve in the dialyzed patient. J Am Soc Nephrol. 2000;11:778-83.

9. Khatri PJ, Webb JG, Rodes-Cabau J, Fremes SE, Ruel M, Lau K, et al. Adverse effects associated with transcatheter aortic valve implantation: a meta-analysis of contemporary studies. Ann Intern Med. 2013;158:35-46. 
10. Webb JG, Altwegg L, Boone RH, Cheung A, Ye J, Lichtenstein S, et al. Transcatheter aortic valve implantation: impact on clinical and valve-related outcomes. Circulation. 2009;119:3009-16.

11. Rosner MH, Okusa MD. Acute kidney injury associated with cardiac surgery. Clin J Am Soc Nephrol. 2006;1:19-32.

12. Aregger F, Wenaweser P, Hellige GJ, Kadner A, Carrel T, Windecker S, et al. Risk of acute kidney injury in patients with severe aortic valve stenosis undergoing transcatheter valve replacement. Nephrol Dial Transplant. 2009;24:2175-9.

13. Diez C, Mohr P, Girndt M, Puehler T, Haneya A, Silber RE, et al. Impact of estimated glomerular filtration rate after valve and combined valve and coronary surgery. ASAIO J. 2010;56:543-9.

14. Van Linden A, Kempfert J, Rastan AJ, Holzhey D, Blumenstein J, Schuler G, et al. Risk of acute kidney injury after minimally invasive transapical aortic valve implantation in 270 patients. Eur J Cardiothorac Surg. 2011;39:835-42; discussion 42-3.

15. Gummert JF, Bucerius J, Walther T, Doll N, Falk V, Schmitt DV, et al. Requirement for renal replacement therapy in patients undergoing cardiac surgery. Thorac Cardiovasc Surg. 2004;52:70-6.

16. McCullough PA. Contrast-induced acute kidney injury. J Am Coll Cardiol. 2008; 51:1419-28.

17. Podolecka E, Chmielak Z, Demkow M, Michałek P, Księżycka-Majczyńska E, Chojnowska SL, et al. Does contrast agent injection during trans-catheter aortic valve implantation negatively affect kidney function? Kardiologia Polska. 2011; 69:251-5.

18. Strauch JT, Scherner MP, Haldenwang PL, Pfister R, Kuhn EW, Madershahian N, et al. Minimally invasive transapical aortic valve implantation and the risk of acute kidney injury. Ann Thorac Surg. 2010;89:465-70.

\section{Discussion}

Dr Wilson Szeto (Philadelphia, Pa). Tom, fantastic presentation, well-written manuscript. Thank you in advance for sending the manuscript to us for review. You and your colleagues at Emory should be congratulated on such a well-timed study. As you know, for patients with severe renal impairment, there is really not a whole lot of data regarding the role of TAVR in this patient population. As you know, that is an exclusion for the PARTNER trial.

You have nicely demonstrated that, in this population in a center of excellence, mortality can be kept at $4.4 \%$ despite their significant comorbidities. So, I congratulate you on that.

A few comments in terms of the data and I will follow up with 3 questions. First, I would reconsider your conclusion that TAVR mitigates the long-term effect of severe renal dysfunction on survival outcome. In your survival curve in the severe renal impairment group undergoing TAVR, there were I think 3 patients at 1-year follow-up. I would caution as calling that long-term outcome and survival improvement.

Number 2, as you so elegantly displayed on your preoperative demographic slides, these clearly are 2 separate sets of patients: the surgical patients and the TAVR patients were different. In your manuscript, you share that the 4-year survival in the surgical group was $82.4 \%$ versus $26 \%$ in the TAVR group. So, clearly, again, this emphasizes that these are different cohorts.

But, let's focus on why we are interested in this abstract, which is the role of TAVR in patients with severe renal dysfunction. So, 3 questions. I will ask them in sequence, and I will give you a chance to answer.

The first one. Just out of curiosity, what was the percentage or the ratio of TF versus transapical and direct aortic? And, as you know, this is not so much a reflection of technique but also a reflection of patient comorbidities. Can you comment on that in terms of your experience in the TAVR group?
Dr Nguyen. Thank you, Dr Szeto, for your thoughtful and constructive comments of the presentation and the manuscript.

Of our patients, $60 \%$ were transfemoral, $30 \%$ were transapical, and the rest were transaortic. When we looked at access as a measure of outcome, we found that both transfemoral and transapical access increased postoperative GFR of near-equal magnitude. We did not appreciate this increase with the transaortic subgroup.

Dr Szeto. Second question. Looking specifically at patients with severe renal impairment, because that is really the group we are interested in because this is the set of patients that we do not have a whole lot of data on, you stated in your manuscript that development of new postoperative renal failure was significantly higher in surgical AVR patients. At the same time, the preoperative baseline creatinine was also higher in that group. So, the saying goes, not all renal impairment patients are the same. Can you further elaborate on the specific characteristics of their renal impairment? What was the breakdown between patients with severe renal impairment but not on dialysis versus the patients on dialysis? And for patients on dialysis, how long had they been on dialysis?

Dr Nguyen. That is a great question. Unfortunately, the data were queried from the STS database, so we do not have information on the duration of hemodialysis. We do know that, in our SAVR subgroup, roughly $60 \%$ were on hemodialysis, and interestingly enough, the death rate for our SAVR group on hemodialysis was $14 \%$.

Looking at our TAVR subgroup, approximately $34 \%$ were on hemodialysis, and our death rate was $0 \%$.

Dr Szeto. And, the last question is sort of a bigger picture patient selection question. Your group has shown that we can do this safely in a 30 -day period with a $4.4 \%$ mortality, even in patients with severe renal insufficiency. As you know, over the last 4 years, we have struggled with the question of futility versus utility. There are patients, as you know, that are so sick and considered futile for TAVR, the so-called cohort Cs. Based on your data, what can you share with the rest of us in terms of recommendations for patient selection when someone comes in your clinic who has aortic stenosis whom you think are either high risk or inoperable and have severe renal insufficiency or dialysis? Should we be treating these patients with TAVR or not? Other groups, such as the Dallas group, have had disappointing early data, and they have stopped doing so. I would like to thank the Association for the privilege to discuss this paper.

Dr Nguyen. Your last comment is really the million dollar question, specifically, what do we do with patients with end-stage renal disease with severe aortic stenosis? At Emory, we treat each of these patients on a case-by-case basis. So, for the young ESRD patient with a relatively low STS score and minimal comorbidities, then we will approach TAVR with relatively low reluctance. On the other hand, our research and other publications suggested that patients with severe COPD and end-stage renal disease are those patients that we tend to shy away from. But, for the most part, we do try to approach these patients on a case-by-case basis, and we do not necessarily exclude just because they have end-stage renal disease or are on hemodialysis.

Dr Szeto. How about newly placed on hemodialysis versus being on it for 5 to 8 years, is that also a screening tool for you as well, the duration of time they have been on hemodialysis? 
Dr Nguyen. Certainly, I think the duration is an important variable to consider, and we are more aggressive if a patient has only recently been on hemodialysis.

Dr Harold Lazar (Boston, Mass). As we all know, the mortality and the long-term survival for patients with chronic renal failure on dialysis who receive a valve replacement, their 3-year survival has been reported to be as low as $25 \%$, and a lot of people think that maybe TAVR might be a good indication for that. Do you have any long-term data, though, as far as the durability of these valves? Do these valves last that long in patients who have chronic renal failure on dialysis, are they more prone to calcification, do they have higher gradients?

Dr Nguyen. Unfortunately, the valves are tissue valves, and, in theory, we assume that they will last just as long as our bioprosthetic valves, roughly 10 to 15 years, but the reality is we do not know. The PARTNER trial started in 2007, and we do not have long-term data.

Dr Ralph Damiano (St Louis, Mo). I have a couple of questions for you. First of all, did you look at the timing of the preoperative cardiac catheterization in the 2 groups and whether that may have influenced the incidence of renal insufficiency, particularly in those that had progression of renal dysfunction? Certainly, the UVA group has shown that if you perform the catheterization right before the surgery, it is associated with worsening renal function as opposed to doing it at some distance prior to surgery. At least I know in our institution for valve procedures, they tend to come in the day before and get a catheterization and then go right to surgery. For our transcatheter valves, the catheter is often done weeks before surgery. Have you looked at the timing of the cardiac catheterization as a variable that may have predicted worse outcome in patients, particularly who had an elevated creatinine but have not yet gone on dialysis?

Dr Nguyen. As you alluded to, the TAVR workup is fairly comprehensive and most of the patients have their workup completed weeks prior to valve implantation. So, it is rare that we will catheterize the patient the day prior to surgery. So, by the time they are getting the TAVR, the potential nephrotoxic effects of the contrast have subsided. There have been other studies that have clumped these patient cohorts with a left heart catheterization and then the TAVR, and they also appreciate a slight increase in GFR postoperatively.
The interesting point from a more philosophical stand point is for the kidneys, what is really worse, is it the cardiopulmonary bypass or is it the contrast load? And, our data seem to suggest that the contrast load is less deleterious than the cardiopulmonary bypass run. And, if you think about it also, the contrast that we used was roughly around $150 \mathrm{~mL}$. When we do a CT angiogram of the chest, abdomen and pelvis, that is about $150 \mathrm{~mL}$. So, if you are doing a CT angiogram on a patient, it is roughly about the same amount of contrast that we use for our TAVR patients. We do try to be judicious about the contrast load for the patients with severe renal dysfunction, and our average contrast load for these patients is roughly 70 to $80 \mathrm{~mL}$.

Dr Damiano. I will ask my question again. You compared the 2 groups, surgical versus transcatheter, and my question is, was the timing of the cardiac catheterization different in those 2 groups, because at least in our institution it is, and would that have influenced at all your results?

Dr Nguyen. This study was not designed as a superiority study. It was designed as an intergroup comparison looking at trends within the surgical AVR and within the TAVR group. To actually compare the 2 groups, the best approach would be a propensity-matched analysis in which we do not have a large enough patient population, although this is the largest series known to date looking at TAVR patients with varying degrees of renal dysfunction.

Dr Damiano. And, then, one quick last question. You mentioned that in the dialysis patients that you had much higher mortality in the surgical than in the transcatheter group, because you said in patients on dialysis there were no deaths. Admittedly, it is a small group.

Dr Nguyen. Correct.

Dr Damiano. What was the cause of death in these dialysis patients and did that differ between the 2 groups? When you are talking about the potential mortality benefit of transcatheter valve replacement in these patients with end-stage renal disease, where is that benefit? Is this early or late death, was the cause of death somehow related to progression of renal dysfunction, or was this all-cause mortality? I want to get some feeling for when did the patients die and what was the cause of death?

Dr Nguyen. For those specific end-stage renal disease patients on hemodialysis, we looked at short-term mortality. 